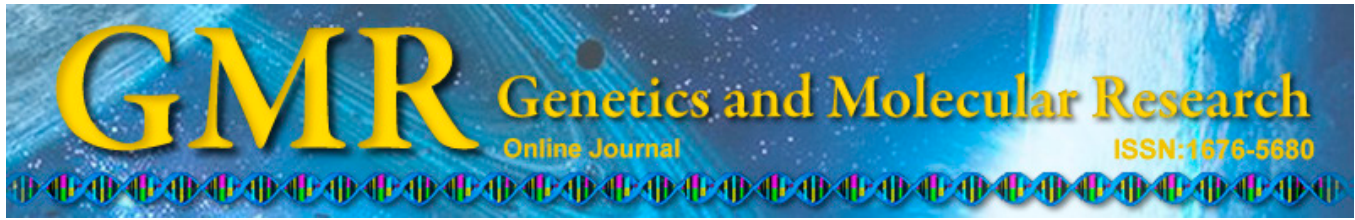

\title{
Expression of c-myc and mutation of the $K R A S$ gene in patients with ovarian mucinous tumors
}

\author{
X.S. $\mathrm{Li}^{1}$, J. Sun ${ }^{2}$ and X.L. He \\ ${ }^{1}$ Chongqing Three Gorges Medical College, Chongqing, China \\ ${ }^{2}$ Liangping County People's Hospital of Chongqing, Liangping, China \\ ${ }^{3}$ Chongqing Three Gorges Central Hospital, Chongqing, China \\ Corresponding author: X.L. He \\ E-mail: hexlctgch@163.com
}

Genet. Mol. Res. 14 (3): 10752-10759 (2015)

Received January 8, 2015

Accepted May 5, 2015

Published September 9, 2015

DOI http://dx.doi.org/10.4238/2015.September.9.14

ABSTRACT. We examined the expression of c-myc and mutations in
the $K R A S$ gene in ovarian mucinous tumors to explore the pathogenesis
of these tumors and the feasibility of targeted gene therapy. Expression
of c-myc protein and mutations in the $K R A S$ gene in 24 cases of ovarian
mucinous cystadenoma, 46 cases of ovarian borderline mucinous
cystadenoma, and 46 cases of ovarian mucinous cystadenocarcinoma
were detected using the immunohistochemistry PV- 9000 -step
method and polymerase chain reaction-restriction fragment length
polymorphism. The positive expression rates of c-myc in ovarian
mucinous cystadenoma, borderline mucinous cystadenoma, and
cystadenocarcinoma were $0,39.1$, and $65.2 \%$, respectively $(\mathrm{P}<0.01)$,
while the mutation rates in $K R A S$ were $0,39.1$ and $13.0 \%$, respectively.
The mutation rate of the borderline group was significantly higher,
while rates in the other 2 groups were similar $(\mathrm{P}>0.05)$. c-myc was
not correlated with clinical stage, pathological grade, or age of patients
with ovarian mucinous cystadenocarcinoma or borderline mucinous
cystadenoma $(\mathrm{P}>0.05)$, but was correlated with tumor size $(\mathrm{P}<0.05)$.
Mutations in $K R A S$ were not correlated with clinical stage or tumor size
in patients with borderline mucinous cystadenoma $(\mathrm{P}>0.05)$, whereas it 
was correlated with age $(\mathrm{P}<0.05)$. In borderline mucinous cystadenoma, c-myc expression and KRAS mutations were not correlated $(\mathrm{P}>0.05)$. $\mathrm{c}-\mathrm{myc}$ is involved in the formation of ovarian borderline mucinous cystadenoma and mucinous cystadenocarcinoma, and the KRAS gene may contribute to the formation of borderline mucinous cystadenoma.

Key words: c-myc; KRAS; Mucinous; Ovarian tumor

\section{INTRODUCTION}

Ovarian cancer is one of the three malignant tumors of the female reproductive system and has particularly high mortality rate because it cannot be diagnosed until an advanced stage (Jemal et al., 2004). As an oncogene belonging to the myc family, c-myc plays an important regulatory role in gene transcription; in the case of tumors, c-myc shows over-amplification and sequence rearrangement. The KRAS gene is a member of the human oncogene RAS family. K-Ras protein participates in cell cycle regulation with downstream signaling proteins and is closely associated with the survival, proliferation, migration, metastasis, and vascularization of tumors. Upon mutation, $K R A S$ is permanently activated and then fails to produce normal K-Ras protein, leading to cancer by disturbing intracellular signal transduction and cell proliferation (He et al., 2010). In this study, the relationship between c-myc protein expression and $K R A S$ gene mutation in ovarian mucinous tumors was analyzed to clarify their roles in these tumors.

\section{MATERIAL AND METHODS}

\section{Sample collection}

This study was approved by the Ethics Committee of Chongqing Three Gorges Central Hospital, and written consent was obtained from all patients. Ovarian mucinous cystadenocarcinoma samples were collected from 46 cases treated in Chongqing Three Gorges Central Hospital from January 2000 to June 2012. The patients were aged 31-74 years (average age of 48 years). The samples were classified into 21 cases of Stage 1, 22 cases of Stage 2, and 3 cases of Stage 3, and they were also pathologically classified into 23 cases of FIGO Grade I, 7 cases of Grade II, and 16 cases of Grade III. Additionally, 46 samples of ovarian borderline mucinous cystadenoma were pathologically classified into 40 cases of Grade I and 6 cases of Grade III. Another 24 samples of ovarian mucinous cystadenoma were used as controls. None of the patients had received radiotherapy, chemotherapy, or hormone therapy before surgeries, and complete clinical data were collected. All patients were diagnosed using pathological methods, and hematoxylin and eosin paraffin sections were evaluated by 2 experienced pathologists.

\section{Reagents and methods}

Ready-to-use c-myc mouse anti-human monoclonal antibody was purchased from Fuzhou Maixin Biotech. Co., Ltd. (Fujian, China). Pepsin and PV-9000 2-step immunohistochemical kits were obtained from Life Technologies (Carlsbad, CA, USA). The immuno- 
histochemistry PV-9000 2-step assay was performed according to the kit instructions using phosphate-buffered saline instead of primary antibody as the negative control and a known positive sample as the positive control. The DNA extraction kit for paraffin-embedded tissues and KRAS primers were obtained from Qiagen (Hilden, Germany). The polymerase chain reaction kit and $B s t \mathrm{NI}$ endonuclease were purchased from New England Biolabs (Ipswich, MA, USA). KRAS gene mutations were detected using polymerase chain reaction-restriction fragment length polymorphism.

\section{Results determination}

Based on immunohistochemical results, c-myc was positively expressed in the cytomembrane and cytoplasm. Results were determined when there was no specific staining in negative control images. Cells with evident brownish yellow particles in the cytomembrane or cytoplasm were considered to be positively stained. Ten high-power fields were randomly selected from each section. Percentage of positive cells $<5 \%:(-) ; 5 \% \leq$ percentage of positive cells $<25 \%$ : $(+) ; 25 \% \leq$ percentage of positive cells $<50 \%$ : $(++)$; percentage of positive cells $\geq 50$ : $(+++) .(+)-(+++)$ represent positive expression, and (-) represents negative expression. The KRAS gene mutation was identified based on the presence of an amplification band at 135 base pairs, while the wild-type gene showed a band at $106 \mathrm{bp}$. When the 2 bands coexisted, the brighter band was considered as the result.

\section{Statistical analysis}

All data were analyzed using SPSS 13.0 (SPSS, Inc., Chicago, IL, USA). Immunohistochemical and polymerase chain reaction results were analyzed using $\chi^{2}$ test, Fisher's exact test and Spearman's rank correlation analysis.

\section{RESULTS}

\section{Expression of c-myc in different ovarian mucinous tumors}

The positive expression rates of c-myc in ovarian mucinous cystadenoma, borderline mucinous cystadenoma, and cystadenocarcinoma were $0,39.1$, and $65.2 \%$ respectively, and showed statistically significant differences $(\mathrm{P}<0.01)$ (Table 1 and Figure 1$)$. c-myc was not correlated with the clinical stage, pathological grade, or age of the patients with ovarian mucinous cystadenocarcinoma $(\mathrm{P}>0.05)$, but $\mathrm{c}-\mathrm{myc}$ was correlated with tumor size $(\mathrm{P}<0.05)$ (Table 2). In addition, c-myc was not correlated with the clinical stage, tumor size, or age of the patients with borderline mucinous cystadenoma $(\mathrm{P}>0.05)$ (Table 3$)$.

Table 1. Expression of c-myc in different ovarian mucinous tumors.
\begin{tabular}{lcccccc}
\hline Group & $\mathrm{N}$ & \multicolumn{4}{c}{ c-myc } & \\
\cline { 3 - 6 } & & + & - & Positive rate (\%) & \\
\hline Ovarian mucinous cystadenoma & 24 & 0 & 24 & 0 & \\
Ovarian borderline mucinous cystadenoma & 46 & 18 & 28 & 39.1 & 0.000 \\
Ovarian mucinous cystadenocarcinoma & 46 & 30 & 16 & 65.2 & \\
\hline
\end{tabular}




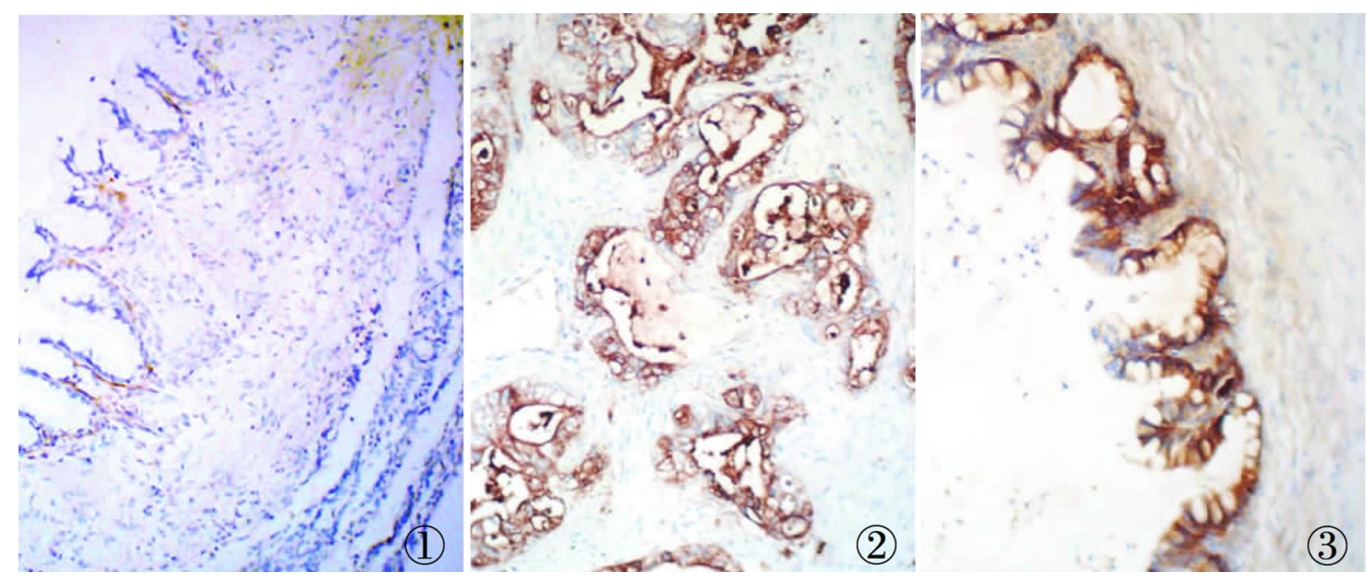

Figure 1. Immunohistochemical staining results of c-myc in different groups. 1. Negative expression of c-myc in ovarian mucinous cystadenoma; 2. positive expression of c-myc in ovarian mucinous cystadenocarcinoma; 3. positive expression of c-myc in borderline mucinous cystadenoma.

\begin{tabular}{|c|c|c|c|c|c|}
\hline \multirow[t]{2}{*}{ Clinical, pathological index } & \multirow[t]{2}{*}{$\mathrm{N}$} & \multicolumn{3}{|c|}{ c-myc } & \multirow[t]{2}{*}{$\mathrm{P}^{*}$} \\
\hline & & + & - & Positive rate (\%) & \\
\hline \multicolumn{6}{|l|}{ Age (years old) } \\
\hline$>50$ & 17 & 11 & 6 & 64.7 & \multirow{2}{*}{1.000} \\
\hline$\leq 50$ & 29 & 19 & 10 & 65.5 & \\
\hline \multicolumn{6}{|l|}{ Tumor diameter $(\mathrm{cm})$} \\
\hline$\geq 2$ & 17 & 15 & 2 & 88.2 & \multirow[t]{2}{*}{0.013} \\
\hline$<2$ & 29 & 15 & 14 & 51.7 & \\
\hline \multicolumn{6}{|l|}{ Pathological grade } \\
\hline 1 & 21 & 11 & 10 & 52.4 & \multirow[t]{2}{*}{0.071} \\
\hline $2-3$ & 25 & 19 & 6 & 76.0 & \\
\hline \multicolumn{6}{|l|}{ Clinical stage } \\
\hline I-II & 30 & 17 & 13 & 56.7 & \multirow[t]{2}{*}{0.159} \\
\hline III-IV & 16 & 14 & 2 & 87.5 & \\
\hline
\end{tabular}

*Fisher's exact test.

\begin{tabular}{|c|c|c|c|c|c|}
\hline \multirow[t]{2}{*}{ Clinical, pathological index } & \multirow[t]{2}{*}{$\mathrm{N}$} & \multicolumn{3}{|c|}{ c-myc } & \multirow[t]{2}{*}{$\mathrm{P}^{*}$} \\
\hline & & + & - & Positive rate (\%) & \\
\hline \multicolumn{6}{|l|}{ Age (years old) } \\
\hline$>50$ & 14 & 4 & 10 & 28.6 & \multirow{2}{*}{0.491} \\
\hline$\leq 50$ & 32 & 13 & 19 & 40.6 & \\
\hline \multicolumn{6}{|l|}{ Tumor diameter $(\mathrm{cm})$} \\
\hline$\geq 2$ & 12 & 7 & 5 & 58.3 & \multirow{2}{*}{0.241} \\
\hline$<2$ & 34 & 10 & 24 & 29.4 & \\
\hline \multicolumn{6}{|l|}{ Clinical stage } \\
\hline I-II & 40 & 14 & 26 & 35.0 & \multirow{2}{*}{0.535} \\
\hline III-IV & 6 & 4 & 2 & 66.7 & \\
\hline
\end{tabular}

*Fisher's exact test. 


\section{$K R A S$ gene mutations in different ovarian mucinous tumors}

The mutation rates of KRAS in ovarian mucinous cystadenoma, borderline mucinous cystadenoma, and cystadenocarcinoma were $0,39.1$, and $13.0 \%$ respectively. The mutation rate in the borderline group was significantly higher $(P<0.01)$ (Table 4 and Figure 2$)$ than those in the other 2 groups, which showed similar values $(\mathrm{P}>0.05)$. The mutation in the KRAS gene was not correlated with the clinical stage or tumor size of patients with borderline mucinous cystadenoma $(\mathrm{P}>0.05)$, whereas the mutation was correlated with age $(\mathrm{P}<0.05)$ (Table 5).

Table 4. KRAS gene mutations in different ovarian mucinous tumors.

\begin{tabular}{llrrrr}
\hline Group & $\mathrm{N}$ & & \multicolumn{2}{c}{ KRAS mutation } & P \\
\cline { 3 - 5 } & & + & \multicolumn{2}{c}{ Positive rate (\%) } \\
\hline Ovarian mucinous cystadenoma & 24 & 0 & 24 & 0.0 & $0.54 *$ \\
Ovarian borderline mucinous cystadenoma & 46 & 18 & 28 & 39.1 & 13.0 \\
Ovarian mucinous cystadenocarcinoma & 46 & 6 & 40 & 0.000 \\
\hline
\end{tabular}

*Fisher's exact test, difference between ovarian mucinous cystadenoma and mucinous cystadenocarcinoma.

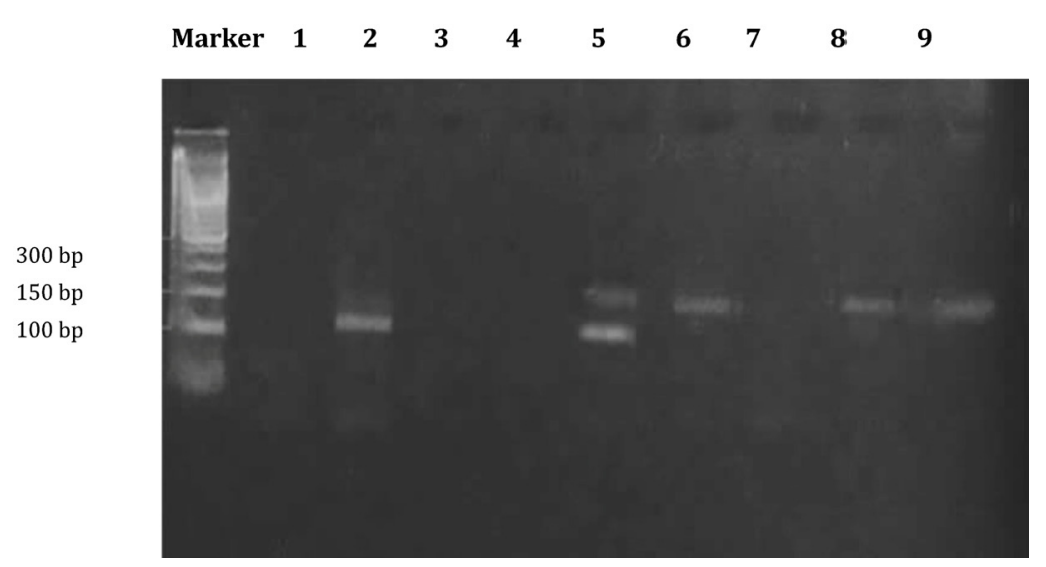

Figure 2. Polymerase chain reactionresults of KRAS DNA in different groups. Lanes 1 and $2=$ Ovarian mucinous cystadenocarcinoma; lanes 3 and 4 = ovarian mucinous cystadenoma; lanes 5-9 = ovarian borderline mucinous cystadenoma; 2, 5: wild-type; 6, 8, 9: mutation; 1, 3, 4, 7: without codon 12 mutation in $K R A S$.

\begin{tabular}{|c|c|c|c|c|c|}
\hline \multirow[t]{2}{*}{ Clinical, pathological index } & \multirow[t]{2}{*}{$\mathrm{N}$} & \multicolumn{3}{|c|}{ KRAS mutation } & \multirow[t]{2}{*}{$\mathrm{P}^{*}$} \\
\hline & & + & - & Mutation rate (\%) & \\
\hline \multicolumn{6}{|l|}{ Age (years old) } \\
\hline$>50$ & 14 & 2 & 12 & 14.3 & 0.037 \\
\hline$\leq 50$ & 32 & 15 & 17 & 46.9 & \\
\hline \multicolumn{6}{|l|}{ Tumor diameter $(\mathrm{cm})$} \\
\hline$\geq 20$ & 12 & 4 & 8 & 33.3 & 1.000 \\
\hline$<20$ & 34 & 13 & 21 & 38.2 & \\
\hline \multicolumn{6}{|l|}{ Clinical stage } \\
\hline I-II & 40 & 16 & 24 & 40.0 & 0.276 \\
\hline III-IV & 6 & 0 & 6 & 0 & \\
\hline
\end{tabular}

\footnotetext{
* Fisher's exact test.
} 


\section{c-myc protein expression in ovarian borderline mucinous cystadenoma}

In borderline mucinous cystadenoma, c-myc expression and the KRAS mutation were not correlated $(\mathrm{P}>0.05)$ (Table 6).

\begin{tabular}{|c|c|c|c|c|}
\hline \multirow[t]{2}{*}{ KRAS } & \multirow[t]{2}{*}{$\mathrm{N}$} & \multicolumn{2}{|c|}{ c-myc } & \multirow[t]{2}{*}{$\mathrm{P}$} \\
\hline & & $\overline{+}$ & $\overline{-}$ & \\
\hline+ & 18 & 6 & 12 & 0.633 \\
\hline
\end{tabular}

\section{DISCUSSION}

Ovarian tumors are common in the female reproductive system and show high incidence and mortality rates as well as difficulty in early diagnosis. Surgical resection of foci or accessories is the preferred treatment of ovarian borderline mucinous cystadenoma. Mucinous cystadenocarcinoma requires resection of bilateral accessories, pelvic lymph node dissection, and chemotherapy, thus severely affecting the quality of life of women of child bearing age. Therefore, it is very important to determine the pathogenesis of ovarian tumors and to develop mild drug therapies other than surgical resection, chemotherapy, and radiotherapy.

As a nuclear transcription factor-type oncogene, c-myc encodes a protein that binds nuclear DNA and regulates transcription. c-myc induces the massive amplification of genes and affects cell proliferation and transformation via other genes and bypass systems (Oster et al., 2003). RAS genes are oncogenes that regulate cell proliferation and apoptosis, including $K R A S, H R A S$, and NRAS, located on the short arms of chromosomes 11, 12, and 1, respectively. Most studies have identified an association between $K R A S$ and human tumors. Additionally, c-myc is a crucial downstream gene of the Ras/Raf pathway, and the overexpression and mutation of Ras induce tumor onset through the transcription and activation of c-myc and cyclinDl (Ischenko et al., 2013; Galuppo et al., 2014).

c-myc protein is positively expressed in gastric cancer, bladder cancer, testicular cancer, pituitary tumors, and endometrial cancer, among others, and is related to their staging, classification, size, and patient age (Huang et al., 2014; Li et al., 2014; Pan et al., 2015; Ishak et al., 2015). Recently, the $c-m y c$ gene was reported to be amplified in patients with early-stage ovarian cancer, which was associated with prognosis (Di et al., 2013). In this study, c-myc was highly expressed in ovarian borderline mucinous cystadenoma and ovarian mucinous cystadenoma, and the positive expression rates increased in the order of ovarian mucinous cystadenoma, borderline mucinous cystadenoma, and mucinous cystadenoma; the values showed statistically significant differences $(\mathrm{P}<0.05)$. c-myc was only correlated with tumor size.

$K R A S$ codons 12 and 13 are also mutated in colorectal cancer (Cejas et al., 2009) and pancreatic cancer (Shen et al., 2008), among others. In targeted therapy for lung cancer, mutations in the KRAS gene arealso closely associated with clinical outcomes (Sung and Cho, 2008). The most common codon 12 was selected as the mutation site in this study. The mutation rate of KRAS in the borderline group was significantly higher $(\mathrm{P}<0.05)$ than those in the other 2 groups, which showed similar values $(\mathrm{P}>0.05)$. These results were consistent with 
those of Mayr et al. (2006). The KRAS gene mutation may be a tumorigenic factor of ovarian borderline mucinous cystadenoma, but it did not promote the progression to cystadenocarcinoma. In addition, the KRAS mutation was related to age $(\mathrm{P}<0.05)$, and patients younger than 50 years were more likely than the elderly to develop cancer.

The c-myc and KRAS genesare present in many tumors and may have clinical potential in targeted therapy. For instance, tumor cell death can be facilitated by promoting KRAS phosphorylation (Bivona et al., 2006), and inhibiting Ras protein post-translational modification and mRNA expression has been used to suppress tumor cell growth. Moreover, inhibiting $K R A S$ mRNA expression using an antisense oligonucleotide suppressed the proliferation of pancreatic cancer cells (Wang et al., 2005). By inhibiting the KRAS gene mutation, metformin suppressed the proliferation of endometrial cancer cells and tumor growth as well as mediated cell apoptosis (Iglesias et al., 2013). Furthermore, c-myc inhibitor both inhibited the proliferation of ovarian cancer cells (Wang et al., 2014) and blocked the growth and metastasis of kidney cancer cells (Zhang et al., 2011), indicating that the $c$-myc and KRAS genes can be used as targets of oncotherapy.

This study showed that c-myc protein expression was not correlated with KRAS gene mutation, and that c-myc played a critical role in the onset and progression of ovarian mucinous tumors. In summary, a c-myc inhibitor may be suitable for treating ovarian mucinous cystadenocarcinoma and borderline mucinous cystadenoma without $K R A S$ gene mutation, but further experimental and clinical studies are necessary.

\section{Conflicts of interest}

The authors declare no conflict of interest.

\section{REFERENCES}

Bivona TG, Quatela SE, Bodemann BO, Ahearn IM, et al. (2006). PKC regulates a farnesyl-electrostatic switch on K-Ras that promotes its association with Bcl-XL on mitochondria and induces apoptosis. Mol. Cell 21: 481-493.

Cejas P, López-Gómez M, Aguayo C, Madero R, et al. (2009). KRAS mutations in primary colorectal cancer tumors and related metastases: a potential role in prediction of lung metastasis. PLoS One 4: e8199.

Di J, Duiveman-de Boer T, Zusterzeel PL, Figdor CG, et al. (2013). The stem cell markers Oct4A, Nanog and c-Myc are expressed in ascites cells and tumor tissue of ovarian cancer patients. Cell Oncol. 36: 363-374.

Galuppo R, Maynard E, Shah M, Daily MF, et al. (2014). Synergistic inhibition of HCC and liver cancer stem cell proliferation by targeting RAS/RAF/MAPK and WNT/B-catenin pathways. Anticancer Res. 34: 1709-1713.

He XY, Chen JX, Zhang Z, Li CL, et al. (2010). The let-7a microRNA protects from growth of lung carcinoma by suppression of k-Ras and c-Myc in nude mice. J. Cancer Res. Clin. Oncol. 136: 1023-1028.

Huang H, Weng H, Zhou H and Qu L (2014). Attacking c-Myc: targeted and combined therapies for cancer. Curr. Pharm. Des. 20: 6543-6554.

Iglesias DA, Yates MS, van der Hoeven D, Rodkey TL, et al. (2013). Another surprise from Metformin: novel mechanism of action via K-Ras influences endometrial cancer response to therapy. Mol. Cancer Ther. 12: 2847-2856.

Ischenko I, Zhi J, Moll UM, Nemajerova A, et al. (2013). Direct reprogramming by oncogenic Ras and Myc. Proc. Natl. Acad. Sci. U. S. A. 110: 3937-3942.

Ishak G, Leal MF, Dos Santos NP, Demachki S, et al. (2015). Deregulation of MYC and TP53 through genetic and epigenetic alterations in gallbladder carcinomas. Clin. Exp. Med. 15: 421-426.

Jemal A, Tiwari RC, Murray T, Ghafoor A, et al. (2004). Cancer statistics, 2004. CA: Cancer J. Clin. 54: 8-29.

Li Z, Meng Q, Yu Q, Zhou Z, et al. (2014). Evaluation of c-myc and CCNE2 amplification in breast cancer with quantitative multi-gene fluorescence in-situ hybridization. Zhonghua Bing Li Xue Za Zhi 43: 455-458.

Mayr D, Hirschmann A, Löhrs U and Diebold J (2006). KRAS and BRAF mutations in ovarian tumors: a comprehensive study of invasive carcinomas, borderline tumors and extraovarian implants. Gynecol. Oncol. 103: 883-887. 
Oster SK, Mao DY, Kennedy J and Penn LZ (2003). Functional analysis of the N-terminal domain of the Myc oncoprotein. Oncogene 22: 1998-2010.

Pan J, Deng Q, Jiang C, Wang X, et al. (2015). USP37 directly deubiquitinates and stabilizes c-Myc in lung cancer. Oncogene 34: 3957-3967.

ShenYM, Yang XC, Yang C and Shen JK (2008). Enhanced therapeutic effects for human pancreatic cancer by application K-ras and IGF-IR antisense oligodeoxynucleotides. World J. Gastroenterol. 14: 5176-5185.

Sung HJ and Cho JY (2008). Biomarkers for the lung cancer diagnosis and their advances in proteomics. BMB Rep. 41: 615-625.

Wang J, Ma X, Jones HM, Chan LL, et al. (2014). Evaluation of the antitumor effects of c-Myc-Max heterodimerization inhibitor 100258-F4 in ovarian cancer cells. J. Transl. Med. 12: 226.

Wang YX, Gao L and Ji ZZ (2005). The study of the effect of antisense oligonucleotide specific to K-ras point mutation on human pancreatic carcinoma cell PC-2. Zhonghua Wai Ke Za Zhi 43: 1387-1390.

Zhang QL, Luo CL, Wu XH, Wang CY, et al. (2011). HepaCAM induces G1 phase arrest and promotes c-Myc degradation in human renal cell carcinoma. J. Cell Biochem. 112: 2910-2919. 